\title{
Burden of cancer attributable to modifiable factors in Japan in 2015
}

\author{
Manami Inoue ${ }^{1,2, *}$, Mayo Hirabayashi', Sarah Krull Abe ', Kota Katanoda ${ }^{3}$, Norie Sawada ${ }^{2}$, Yingsong Lin ${ }^{4}$, \\ Junko Ishihara ${ }^{5}$, Ribeka Takachi ${ }^{6}$, Chisato Nagata ${ }^{7}$, Eiko Saito ${ }^{3}$, Atsushi Goto ${ }^{8}$, Kayo Ueda ${ }^{9}$, Junko Tanaka ${ }^{10}$, \\ Megumi Hori ${ }^{3}$, Tomohiro Matsuda ${ }^{11}$; the Cancer PAF Japan Collaborators \\ ${ }^{1}$ Division of Prevention, Center for Public Health Sciences, National Cancer Center, Tokyo, Japan; \\ ${ }^{2}$ Division of Cohort Research, Center for Public Health Sciences, National Cancer Center, Tokyo, Japan; \\ ${ }^{3}$ Division of Cancer Statistics Integration, Center for Cancer Control and Information Services, National Cancer Center, Tokyo, Japan; \\ ${ }^{4}$ Department of Public Health, Aichi Medical University School of Medicine, Nagakute, Aichi, Japan; \\ ${ }^{5}$ School of Life and Environmental Science, Department of Food and Life Science, Azabu University, Kanagawa, Japan; \\ ${ }^{6}$ Department of Food Science and Nutrition, Graduate School of Humanities and Sciences, Nara Women's University, Nara, Japan; \\ ${ }^{7}$ Department of Epidemiology and Preventive Medicine, Gifu University Graduate School of Medicine, Gifu, Japan; \\ ${ }^{8}$ Yokohama City University, Department of Health Data Science, Graduate School of Data Science, Yokohama, Japan; \\ ${ }^{9}$ Environmental Health Sciences, Graduate School of Global Environmental Studies, Kyoto University, Kyoto, Japan; \\ ${ }^{10}$ Department of Epidemiology, Infectious Disease Control and Prevention, Graduate School of Biomedical and Health Sciences, Hiroshima \\ University, Hiroshima, Japan; \\ ${ }^{11}$ National Cancer Registry Section Center for Cancer Registries Center for Cancer Control and Information Services/Office of International Affairs, \\ Strategic Planning Bureau National Cancer Center, National Cancer Center, Tokyo, Japan.
}

\begin{abstract}
The This study estimated the cancer burden attributable to modifiable factors in Japan in 2015 using the best available epidemiological evidence and a standard methodology. We selected the following factors for inclusion in the estimates, namely tobacco smoking (active smoking and secondhand smoking), alcohol drinking, excess bodyweight, physical inactivity, infectious agents (Helicobacter pylori, hepatitis C virus, hepatitis B virus, human papilloma virus, Epstein-Barr virus, and human T-cell leukemia virus type 1), dietary intake (highly salted food, fruit, vegetables, dietary fiber, red meat, processed meat), exogenous hormone use, never breastfeeding and air pollution, given that these were considered modifiable, in theory at least. We first estimated the population attributable fraction (PAF) of each cancer attributable to these factors using representative relative risks of Japanese and the prevalence of exposures in Japanese around 2005, in consideration of the 10-year interval between exposure and cancer outcomes. Using nationwide cancer incidence and mortality statistics, we then estimated the attributable cancer incidence and mortality in 2015. We finally obtained the PAF for site-specific and total cancers attributable to all modifiable risk factors using this formula, with statistical consideration of the effect of overlap between risk factors. The results showed that $35.9 \%$ of all cancer incidence ( $43.4 \%$ in men and $25.3 \%$ in women) and $41.0 \%$ of all cancer mortality ( $49.7 \%$ in men and $26.8 \%$ in women) would be considered preventable by avoidance of these exposures. Infections and active smoking followed by alcohol drinking were the greatest contributing factors to cancer in Japan in 2015.
\end{abstract}

Keywords: cancer, modifiable factor, population attributable fraction, Japan

\section{Introduction}

The structure of disease in Japan has changed drastically over the past decades, largely due to changes in economics, demographics and lifestyle. Together with rapid aging, the transition from communicable diseases such as tuberculosis and pneumonia to noncommunicable diseases such as cancer has challenged domestic health systems and public health.

Cancer has been the leading causes of death in Japan since 1981 (1). Recent statistics show that cancer accounted for $27.3 \%$ of all deaths $(n=1,381,093)$ (31.1\% of men and $23.2 \%$ of women) in 2019 (1). The national cancer registry documented 980,856 newly diagnosed cases of cancer $(558,874$ men and 421,964 women) in 2018 , suggesting that $65.0 \%$ of men and $50.2 \%$ of women will be diagnosed with cancer at least once in their lifetime (2). For 2035, it is estimated that over 1,172,000 Japanese will be diagnosed with cancer, and 382,000 will die from it (3). Thus, effective cancer prevention and control is crucial to reducing the burden of cancer in Japan. 
It has long been known that many cancers are caused by lifestyle and environmental factors that could potentially be prevented (4), suggesting the possibility of reducing the cancer burden caused by such exposures. However, the pattern of such modifiable factors and pattern of cancer differ among countries and regions, and cancer control policies should accordingly be tailored to reflect the local burden of cancer.

The proportion of preventable cancers is often referred to as the population attributable fraction (PAF). The first quantitative assessment of attributable causes of cancer mortality was reported in 1981 for the US by Doll and Peto (5). More recently, country-specific attributable causes of cancer using PAF have been reported in the US (5-7), Nordic countries (8,9), France (10-12), China (13), South Korea (14), UK (15,16), Australia (17), Canada (18), Germany (19), Brazil (20), Chile (21) and Vietnam (22) as well as Japan (23). In Japan, the burden of cancer attributable to known preventable risk factors was first assessed for the year 2005 (23), in which 55\% of cancer among men and nearly 30\% among women was attributed to preventable risk factors. That study also showed that tobacco smoking and infections were the major causes of cancer in Japan. Of note, the study applied to the prevalence of exposures occurring 15 years before, i.e. around 1990, based on a 15-year time lag between exposure and cancer outcome. This process was hampered by the limited availability of data sources for many exposures around 1990, which obliged the researchers to use less representative data or to exclude such exposures from analysis. Likewise, the number of Japanese epidemiological studies of risk assessment at that time was also limited, which led to insufficient evidence for PAF estimates. The subsequent decade saw the accumulation of additional epidemiological evidence and data on exposures of interest, and national representative data became available for many factors. In addition, the prevalence of many modifiable risk factors in Japan was shown to have dramatically changed by birth cohort. Accordingly, analysis to determine the burden of cancer attributed to such factors should be done with consideration to prevalence among birth cohorts at the time of exposure.

Hence, in this report, we estimated the cancer burden attributable to modifiable factors in Japan in 2015, using the most recent epidemiological evidence.

\section{Methods}

PAF in this project is defined as the fraction of cancer incidence or mortality that is attributable to a particular exposure and that could be avoided if the exposure were eliminated or reduced to an alternative scenario that would result in the lowest risk; or in other words, the theoretical minimum risk exposure distribution. We took several steps to accomplish this goal (Figure S1, https:// www.globalhealthmedicine.com/site/supplementaldata. html? ID =43), namely I. Selection of risk factors with definitions of their theoretical minimum risk exposures and target cancers; II. Acquisition of essential data, namely $i$ ) cancer incidence and mortality statistics in Japan, ii) prevalence of risk factors in Japan, and iii) representative relative risks for each risk factors; and III. Estimation of PAF of cancer attributable to modifiable factors in Japan in 2015. Estimation of PAF was conducted first by risk factor, by specific cancer site. By adding up the obtained PAF of each factor related to each site, with statistical control of the effect of overlap between risk factors, we finally obtained the PAF for total cancers attributable to modifiable factors.

\section{Selection of risk factors with definitions of their theoretical minimum risk exposures and target cancers}

\section{Selection of risk factors and related cancer sites}

Risk factors included in the present PAF estimation were basically selected based on agents classified by the International Agency for Research on Cancer (IARC) as group 1 (carcinogens in humans) (24) and risk factors that were judged as "convincing", with the exception of "convincing" or "probable" for dietary factors, from the Third Expert Report, Diet, Nutrition, Physical Activity and Cancer: a Global Perspective (25). Related cancer sites were also selected from these expert reports, as well as from a report of the US Surgeon General in 2014 (26) for tobacco smoking. Additionally, we referred to domestic comprehensive evaluations, including a report by the Japanese Committee on Smoking and Health in 2016 (27), and a risk assessment by the Research Group for the Development and Evaluation of Cancer Prevention Strategies in Japan (28).

Risk factors meeting the following criteria, as applied in a previous estimate (23), were adopted into the present estimate: 1) there was evidence of a causal association between the factor and at least one type of cancer; 2) prevalence was available from national representative surveys; and 3 ) there were achievable alternative exposure levels that would reduce the risk.

Some established carcinogens, including some types of infectious agents such as Schistosoma hematobium, Opisthorchis viverrini, human immunodeficiency virus (HIV), and aflatoxin, were not included due to their extremely low prevalence in Japan. Furthermore, we did not include occupational exposures, or ultraviolet or radiation exposure, due to a lack of reliable prevalence data in Japan.

\section{Theoretical minimum risk exposure level}

We defined a theoretical minimum risk exposure level for each risk factor included in this estimate. Details are described in the following companion reports, with a focus on the PAF of cancer by each risk factor.

Risk factors, theoretical minimum risk exposure levels, and cancer sites considered in this estimate are 
described in Table 1.

\section{Acquisition of essential data}

i) Cancer incidence and mortality statistics in Japan in 2015

Cancer incidence data in 2015 were estimated using the annual estimate of cancer incidence in 2013 by the Monitoring of Cancer Incidence in Japan Project (MCIJ) on the basis of data collected from population-based cancer registries in Japan (29). Estimation was done using an age and period spline model, a type which is used for short-term projections of cancer incidence in Japan (30). For some of the cancer sites, subsites, or histological subtypes which were not included in this published database, we further asked the MCIJ project to provide such detailed data, with permission for this purpose.

The sex- and age-specific incidence data for target cancers were coded by the International Statistical Classification of Diseases and Related Health Problems, $10^{\text {th }}$ edition (ICD-10) (31), with the morphology code of the International Classification of Disease for Oncology, $3^{\text {rd }}$ edition (ICD-O-3) (32).

The statistical data on cancer mortality from 2015 were obtained from the vital statistics of Japan (33). We obtained sex- and age-specific mortality data by cause of death from available data sources from the Health, Labour, and Welfare Statistics Association (34). As was done for the cancer incidence data, 4-digit ICD-10 codes were used to classify the cause of death.

Table 2 shows the summary of incidence and mortality of cancer data used in this estimate in Japan in 2015.

\section{ii) Prevalence of risk factors in Japan}

The current incidence or mortality of cancer reflects the cumulative effect of past exposures. For most cancers and risk factors, the latent period between "exposure" to the risk factor and the increase in risk of the relevant cancer has not been well established. We assumed that this would be 10 years on average, and thus examined the effects of cancers occurring in 2015 from exposure to risk factors in 2005 . We collected prevalence data

Table 1. Risk factors considered, theoretical minimum risk exposure level, and cancer sites considered

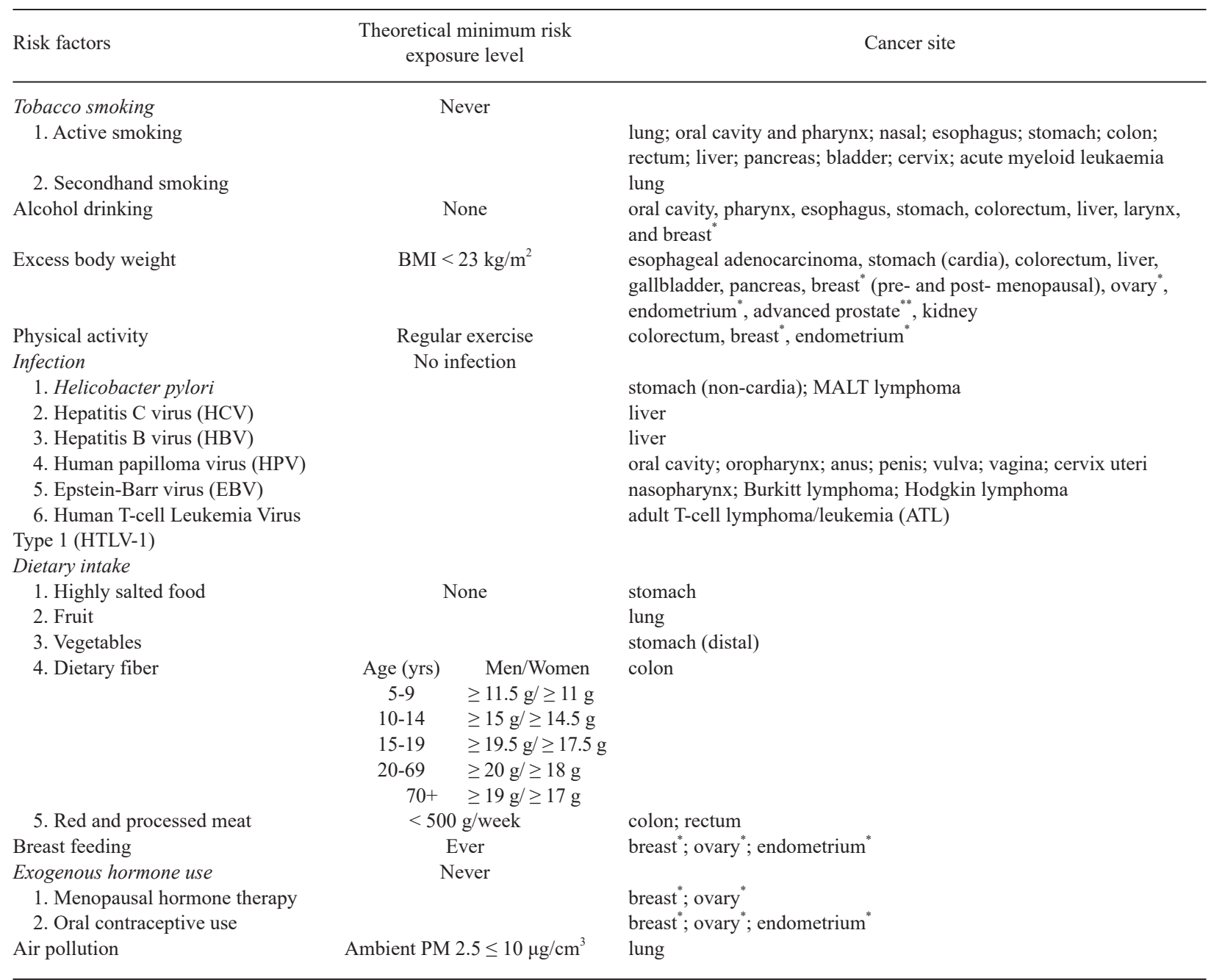

"Calculated for women only. ${ }^{* *}$ Calculated for men only. 
Table 2. Incidence ${ }^{a}$ and mortality ${ }^{b}$ of all and selected sites of cancer in Japan (2015)

\begin{tabular}{|c|c|c|c|c|c|c|c|}
\hline \multirow{2}{*}{ Cancer site } & \multirow{2}{*}{ ICD-10 } & \multicolumn{2}{|c|}{ Men } & \multicolumn{2}{|c|}{ Women } & \multicolumn{2}{|c|}{ Both sexes } \\
\hline & & Incidence & Death & Incidence & Death & Incidence & Death \\
\hline Base of Tongue & $\mathrm{C} 01$ & 654 & 26 & 38 & 2 & 692 & 28 \\
\hline Oral and mouth & $\mathrm{C} 02-\mathrm{C} 06$ & 6,409 & 1,844 & 4,544 & 1,467 & 10,954 & 3,311 \\
\hline Tonsil and Oropharynx & $\mathrm{C} 09-\mathrm{C} 10$ & 2,033 & 798 & 475 & 167 & 2,509 & 965 \\
\hline Nasopharynx & $\mathrm{C} 11$ & 581 & 224 & 277 & 75 & 858 & 299 \\
\hline Other oral pharynx & $\mathrm{C} 00, \mathrm{C} 07-\mathrm{C} 08, \mathrm{C} 12-\mathrm{C} 14$ & 4,802 & 2,366 & 1,150 & 411 & 5,952 & 2,777 \\
\hline Esophagus & $\mathrm{C} 15$ & 19,390 & 9,774 & 3,540 & 1,965 & 22,930 & 11,739 \\
\hline Stomach & $\mathrm{C} 16$ & 91,883 & 30,809 & 42,203 & 15,870 & 134,087 & 46,679 \\
\hline Colon & $\mathrm{C} 18$ & 50,394 & 17,063 & 44,310 & 17,275 & 94,703 & 34,338 \\
\hline Rectum & C19-C20 & 30,433 & 9,755 & 16,401 & 5,606 & 46,835 & 15,361 \\
\hline Anus & $\mathrm{C} 21$ & 521 & 209 & 472 & 202 & 993 & 411 \\
\hline Liver & $\mathrm{C} 22$ & 28,222 & 19,008 & 15,087 & 9,881 & 43,308 & 28,889 \\
\hline Gallbladder & $\mathrm{C} 23$ & 3,721 & 2,532 & 5,190 & 3,716 & 8,911 & 6,248 \\
\hline Pancreas & $\mathrm{C} 25$ & 19,523 & 16,186 & 18,524 & 15,680 & 38,046 & 31,866 \\
\hline Sino-nasal & C30-31 & 1,333 & 392 & 705 & 245 & 2,038 & 637 \\
\hline Larynx & $\mathrm{C} 32$ & 4,630 & 899 & 360 & 72 & 4,990 & 971 \\
\hline Lung & C33-C34 & 83,169 & 53,208 & 40,025 & 21,170 & 123,194 & 74,378 \\
\hline Breast & $\mathrm{C} 50$ & & & 84,709 & 13,584 & 84,709 & 13,584 \\
\hline Vulva & C51 & & & 867 & 262 & 867 & 262 \\
\hline Vagina & $\mathrm{C} 52$ & & & 363 & 151 & 363 & 151 \\
\hline Cervix & $\mathrm{C} 53$ & & & 11,253 & 2,813 & 11,253 & 2,813 \\
\hline Endometrium & $\mathrm{C} 54$ & & & 15,372 & 2,322 & 15,372 & 2,322 \\
\hline Ovary & $\mathrm{C} 56$ & & & 10,166 & 4,676 & 10,166 & 4,676 \\
\hline Penis & $\mathrm{C} 60$ & 412 & 141 & & & 412 & 141 \\
\hline Prostate & C61 & 82,896 & 11,326 & & & 82,896 & 11,326 \\
\hline Kidney & C64 & 13,471 & 3,182 & 5,954 & 1,584 & 19,426 & 4,766 \\
\hline Renal pelvis \& ureter & C65-66 & 5,292 & 2,353 & 3,008 & 1,558 & 8,300 & 3,911 \\
\hline Bladder & C67 & 15,280 & 5,582 & 5,168 & 2,548 & 20,448 & 8,130 \\
\hline Hodgkin disease & $\mathrm{C} 81$ & 805 & 102 & 446 & 58 & 1,251 & 160 \\
\hline Non-Hodgkin Lymphoma & $\mathrm{C} 82-\mathrm{C} 85, \mathrm{C} 96$ & 15,195 & 6,568 & 12,581 & 5,140 & 27,776 & 11,708 \\
\hline Burkitt's lymphoma & $\mathrm{C} 837$ & 170 & 36 & 138 & 20 & 308 & 56 \\
\hline Adult T-cell Lymphoma/Leukemia & C915 & 912 & 446 & 663 & 506 & 1,575 & 952 \\
\hline Acute Myeloid leukemia & C920, C924, C925 & 2,970 & 2,968 & 1,983 & 1,808 & 4,953 & 4,776 \\
\hline All sites & $\mathrm{C} 00-\mathrm{C} 96, \mathrm{C} 97^{\mathrm{c}}$ & 549,241 & 219,508 & 408,572 & 150,838 & 957,813 & 370,346 \\
\hline
\end{tabular}

${ }^{\mathrm{a}}$ Derived from Monitoring of Cancer Incidence in Japan project. ${ }^{\mathrm{b}}$ Derived from the vital statistics of Japan. ${ }^{\mathrm{c}} \mathrm{C} 97$ is included in death only.

of exposure to each risk factor from different sources, prioritizing Japanese national representative surveys. For exogenous hormone use (hormone replacement therapy and oral contraceptive use), the latency period was not considered since cancer risk decreases rapidly after cessation (35).

\section{iii) Representative relative risk for each risk factor}

Relative risk (RR) data were obtained from epidemiological studies identified from different sources, including PubMed, Ichushi-web, and other literature searches, either in English or Japanese. We used studies that reported RR and corresponding 95\% confidence intervals (CIs). We employed priority ranking for the inclusion and selection of representative RRs. Among these studies, meta-analyses that included pooled analyses of Japanese populations were the most preferred source of RR. When such meta-analyses were not available, RR was derived from the most comprehensive Japanese studies. Cohort studies were prioritized over case-control studies. If no RR derived from Japanese population sources were available, the data from other Asian populations were used, followed by non-Asian populations. Within meta- and pooled analyses where multiple RRs were available, RRs were selected based on characteristics that were most relevant to the evidence.

III. Estimation of PAF of cancer attributable to modifiable factors in Japan in 2015

\section{Cancer site-specific PAF estimation by each risk factor}

Cancer site-specific PAFs of each risk factor were calculated separately by sex and age groups and the agespecific attributed cases or deaths were aggregated to obtain the total number of attributed cases or deaths. In this study, we estimated PAF by a couple of methods. When exposure to a risk factor was dichotomous, a standard PAF formula proposed by Levin (36) was applied:

$$
P A F=\frac{P(R R-1)}{P(R R-1)+1}
$$


where $P$ is prevalence and RR is relative risk.

When there are multiple categories to be considered in the PAF calculation, the modified formula for $\kappa$ multiple categories by Hanley was used (37):

$$
\begin{gathered}
P A F=\frac{\sum_{K=1}^{\mathrm{K}} P_{K}\left(R R_{K}-1\right)}{\sum_{K=1}^{\mathrm{K}} P_{K}\left(R R_{K}-1\right)+1} \\
\kappa=1,2, \ldots, \mathrm{K}
\end{gathered}
$$

where $P$ is prevalence, $\mathrm{R}$ is relative risk, and $\mathrm{K}$ is the number of categories for the risk factor.

For some risk factors, risk of cancer per unit increase in exposure and average RR for the whole population based on the average exposure, with the assumption of a log-linear relationship between exposure and risk, was calculated using the following formula (11):

$$
\begin{gathered}
P A F=\frac{R i s k-1}{R i s k} \\
R i s k=\exp ^{[\ln (\text { risk per unit) } \times \text { average exposure level }]}
\end{gathered}
$$

For some infectious agents, PAF was calculated using the prevalence of the infectious agent in cases only and the RR associated with that infection (37):

$$
P A F=P c \times \frac{R R-1}{R R}
$$

where Pc is prevalence among cases.

\section{Total cancer PAF estimation by individual risk factors}

Cancer site-specific PAF was multiplied by the number of incidence or mortality of site-specific cancer to obtain the site-specific number of attributable cancer incidence and mortality. By summing these sitespecific attributed numbers of cancer incidence and mortality, we obtained the attributed number of total cancer incidence and mortality. Total cancer PAF was then obtained by dividing the number of attributed total cancer incidence and mortality by the number of observed total cancer incidence and mortality.

\section{Site-specific and total cancer PAF estimation considering all modifiable risk factors}

Risk factor-specific PAF of each site of cancer and total cancers was further aggregated to estimate total PAF with consideration of all modifiable risk factors. Most cancers are caused by multiple risk factors, and PAF for individual risk factors for the same cancer sites can therefore overlap and add up to over $100 \%$. To obtain the PAF of total modifiable risk factors, we took into account the degree of overlap of PAF under the assumption of independence of exposures and risk (38). Combined PAF for the two risk factors A and B can be calculated by the following formula (38):

$$
P A F_{A B}=1-\left(1-P A F_{A}\right) \times\left(1-P A F_{B}\right)
$$

This formula can be generalized to more than two risk factors.

We finally obtained the PAF for site-specific and total cancers attributable to all modifiable risk factors using this formula with statistical consideration of the effect of overlap between risk factors. These PAFs were then used to estimate the number of attributable incident cases and deaths of site-specific and total cancer.

\section{Sensitivity analysis of PAFs}

Calculation of the PAF is determined by the choice of estimated exposure prevalence at the population level and the RR associated with the risk factor. Use of a point estimate of RR involves uncertainty. To account for differences in PAF due to uncertainty in the RR estimation, we performed sensitivity analyses on the PAFs by using the lower and upper bounds of the $95 \%$ CIs for the RR estimates.

\section{Results}

The estimated PAFs of total and associated cancer sites for each modifiable factor were reported in separate articles in detail (39-48), and are summarized in Table 3. Table S1 (cancer incidence) and S2 (cancer mortality) (online data, https://www.globalhealthmedicine.com/ site/supplementaldata.html?ID=42) describe the PAF estimates for relevant cancer sites and types and total cancers for each modifiable factor. Overall, $35.9 \%$ of all cancers diagnosed in Japan in 2015 (43.4\% in men and $25.3 \%$ in women) were attributable to modifiable risk factors of cancer. The corresponding figure for cancer mortality was $41.0 \%$ for both sexes $(49.7 \%$ in men and $26.8 \%$ in women). Infections and active smoking are the most important modifiable factors for cancer in Japan, followed by alcohol drinking, given that $16.6 \%$ of cancer incidence is explained by infections, $15.2 \%$ by active smoking, and $6.2 \%$ by alcohol drinking. Cancer mortality showed similar figures, among which $19.6 \%$ of cancer deaths were explained by active smoking, $17.7 \%$ by infections, and $6.5 \%$ by alcohol drinking. There was a difference in the pattern of PAF by sex (Figure 1), with the major attributable factors for men being active smoking (23.6\% for incidence and 29.8\% for mortality), infections $(18.1 \%$ for incidence and $18.5 \%$ for mortality) and alcohol drinking (8.3\% for incidence and $8.8 \%$ for mortality), versus infections (14.7\% for incidence and $16.5 \%$ for mortality), alcohol drinking (3.5\% for incidence and $3.0 \%$ for mortality) and active smoking (4.0\% for incidence and $4.7 \%$ for mortality) for women. In both sexes, other factors such as secondhand smoking, excess body weight, physical 
Table 3. Number and population attributable fraction (PAF, \%) of cancer incidence and mortality attributable to selected modifiable risk factors in Japan in 2015

\begin{tabular}{|c|c|c|c|c|c|}
\hline \multirow{2}{*}{ Risk factor } & \multirow{2}{*}{$\begin{array}{l}\text { Theoretical minimum risk } \\
\text { exposure level }\end{array}$} & \multicolumn{2}{|c|}{ Incidence } & \multicolumn{2}{|c|}{ Mortality } \\
\hline & & PAF (\%) & number & $\operatorname{PAF}(\%)$ & number \\
\hline \multicolumn{6}{|l|}{ Men } \\
\hline Total Number & & & 549,241 & & 219,508 \\
\hline Active smoking & Never & 23.6 & 129,502 & 29.8 & 65,417 \\
\hline Secondhand smoking & Never & 0.2 & 1,095 & 0.3 & 735 \\
\hline Alcohol drinking & None & 8.3 & 45,360 & 8.8 & 19,406 \\
\hline Excess body weight & $\mathrm{BMI}<23 \mathrm{~kg} / \mathrm{m}^{2}$ & 1.0 & 5,539 & 1.0 & 2,197 \\
\hline Physical inactivity & Regular exercise & 1.0 & 5,509 & 0.9 & 1,942 \\
\hline Infections & No infection & 18.1 & 99,481 & 18.5 & 40,580 \\
\hline Highly salted food consumption & No intake & 3.0 & 16,249 & 2.5 & 5,571 \\
\hline Vegetable consumption & $\geq 350 \mathrm{~g} /$ day & 0.3 & 1,667 & 1.0 & 2,197 \\
\hline Fruit consumption & $\geq 100 \mathrm{~g} /$ day & 0.1 & 570 & 0.1 & 253 \\
\hline Dietary fiber consumption & sufficient consumption* & 1.2 & 6,837 & 1.0 & 2,124 \\
\hline Red and processed meat consumption & $<500 \mathrm{~g} /$ week & 0.0 & 75 & 0.0 & 16 \\
\hline Air pollution & Ambient PM $2.5 \leq 10 \mu \mathrm{g} / \mathrm{cm}^{3}$ & 1.6 & 8,788 & 2.6 & 5,682 \\
\hline Above all risk factors (adjusted for overlaps) & & 43.4 & 238,497 & 49.7 & 109,151 \\
\hline \multicolumn{6}{|l|}{ Women } \\
\hline Total Number & & & 408,572 & & 150,838 \\
\hline Active smoking & Never & 4.0 & 16,263 & 4.7 & 7,105 \\
\hline Secondhand smoking & Never & 0.9 & 3,483 & 1.3 & 1,932 \\
\hline Alcohol drinking & None & 3.5 & 14,477 & 3.0 & 4,522 \\
\hline Excess body weight & $\mathrm{BMI}<23 \mathrm{~kg} / \mathrm{m}^{2}$ & 0.3 & 1,228 & 0.3 & 429 \\
\hline Physical inactivity & Regular exercise & 1.6 & 6,521 & 0.8 & 1,153 \\
\hline Infections & No infection & 14.7 & 59,893 & 16.5 & 24,935 \\
\hline Highly salted food consumption & No intake & 1.6 & 6,497 & 1.7 & 2,510 \\
\hline Vegetable consumption & $\geq 350 \mathrm{~g} /$ day & 0.1 & 564 & 0.3 & 429 \\
\hline Fruit consumption & $\geq 100 \mathrm{~g} /$ day & 0.0 & 69 & 0.0 & 18 \\
\hline Dietary fiber consumption & sufficient consumption* & 0.8 & 3,143 & 0.9 & 1,370 \\
\hline Red and processed meat consumption & $<500 \mathrm{~g} /$ week & 0.0 & 0 & 0.0 & 0 \\
\hline Breastfeeding & Ever & 0.3 & 1,232 & 0.1 & 202 \\
\hline Exogenous hormone use & Never & 0.4 & 1,454 & 0.2 & 279 \\
\hline Air pollution & Ambient PM $2.5 \leq 10 \mu \mathrm{g} / \mathrm{cm}^{3}$ & 0.7 & 3,014 & 1.0 & 1,582 \\
\hline Above all risk factors (adjusted for overlaps) & & 25.3 & 103,237 & 26.8 & 40,495 \\
\hline \multicolumn{6}{|l|}{ Both sexes } \\
\hline Total Number & & & 957,813 & & 370,346 \\
\hline Active smoking & Never & 15.2 & 145,765 & 19.6 & 72,521 \\
\hline Secondhand smoking & Never & 0.5 & 4,579 & 0.7 & 2,667 \\
\hline Alcohol drinking & None & 6.2 & 59,838 & 6.5 & 23,929 \\
\hline Excess body weight & $\mathrm{BMI}<23 \mathrm{~kg} / \mathrm{m}^{2}$ & 0.7 & 6,767 & 0.7 & 2,625 \\
\hline Physical inactivity & Regular exercise & 1.3 & 12,030 & 0.8 & 3,095 \\
\hline Infections & No infection & 16.6 & 159,374 & 17.7 & 65,515 \\
\hline Highly salted food consumption & No intake & 2.4 & 22,746 & 2.2 & 8,081 \\
\hline Vegetable consumption & $\geq 350 \mathrm{~g} /$ day & 0.2 & 2,231 & 0.7 & 2,625 \\
\hline Fruit consumption & $\geq 100 \mathrm{~g} /$ day & 0.1 & 640 & 0.1 & 271 \\
\hline Dietary fiber consumption & sufficient consumption ${ }^{*}$ & 1.0 & 9,979 & 0.9 & 3,494 \\
\hline Red and processed meat consumption & $<500 \mathrm{~g} /$ week & 0.0 & 75 & 0.0 & 16 \\
\hline Breastfeeding & Ever & 0.1 & 1,232 & 0.1 & 202 \\
\hline Exogenous hormone use & Never & 0.2 & 1,454 & 0.1 & 279 \\
\hline Air pollution & Ambient PM $2.5 \leq 10 \mu \mathrm{g} / \mathrm{cm}^{3}$ & 1.2 & 11,922 & 2.0 & 7,264 \\
\hline Above all risk factors (adjusted for overlaps) & & 35.9 & 344,230 & 41.0 & 151,672 \\
\hline
\end{tabular}

"Theoretical minimum risk exposure level for dietary fiber consumption by age group: Men 5-9: $\geq 11.5 \mathrm{~g}, 10-14: \geq 15 \mathrm{~g}, 15-19: \geq 19.5 \mathrm{~g}, 20-69: \geq$ $20 \mathrm{~g}, 70+: \geq 19 \mathrm{~g}$; Women 5-9: $\geq 11 \mathrm{~g}, 10-14: \geq 14.5 \mathrm{~g}, 15-19: \geq 17.5 \mathrm{~g}, 20-69: \geq 18 \mathrm{~g}, 70+: \geq 17 \mathrm{~g}$. The number of both sexes is not equal to the sum of men and women due to rounding.

inactivity, highly salted food intake, fruit intake, vegetable intake, dietary fiber intake, red and processed meat intake, breast feeding, exogenous hormone use, and air pollution accounted for a small share of both cancer incidence and mortality.

Estimated PAFs of all modifiable factors aggregated for cancer sites/types associated with one or more modifiable factors are shown in Table 4. Cancer of the uterine cervix and adult T-cell leukemia/lymphoma had the highest fractions of potentially modifiable factors $(100 \%)$ for which the infectious agents were considered necessary causal factors. Other cancer sites/types with 

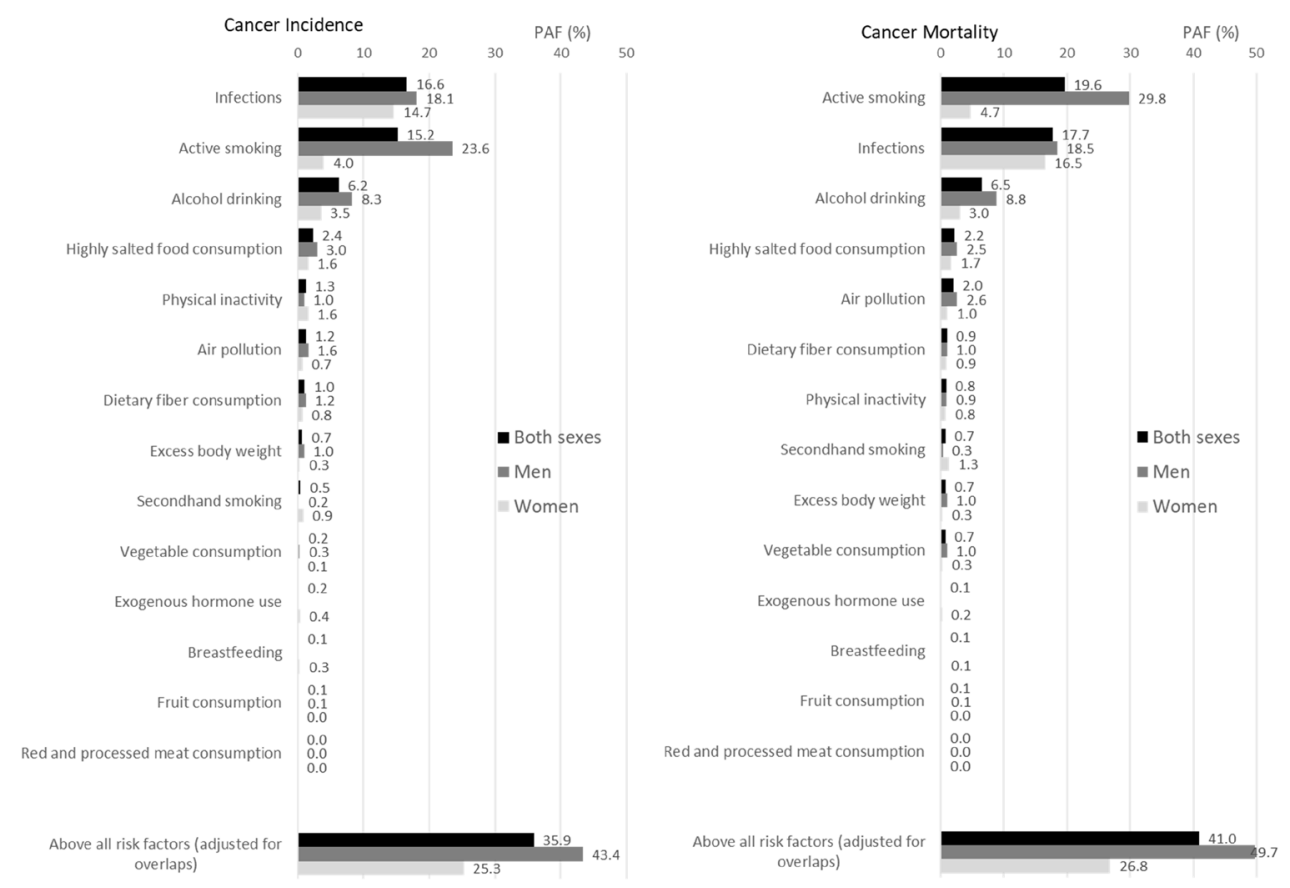

Figure 1. Population attributable fraction (PAF, \%) of cancer incidence and mortality in Japan in 2015 by exposure.

Table 4. Summary table of population attributable fraction of cancer incidence and mortality in Japan in 2015 by cancer site

\begin{tabular}{|c|c|c|c|c|c|c|c|}
\hline \multirow{3}{*}{ Site } & \multirow{3}{*}{ ICD-10 } & \multicolumn{6}{|c|}{ Population Attributable Fraction (\%) } \\
\hline & & \multicolumn{2}{|c|}{ Men } & \multicolumn{2}{|c|}{ Women } & \multicolumn{2}{|c|}{ Both sexes } \\
\hline & & Incidence & Mortality & Incidence & Mortality & Incidence & Mortality \\
\hline Base of Tongue & $\mathrm{C} 01$ & 72.3 & 71.8 & 58.4 & 56.0 & 68.9 & 68.3 \\
\hline Oral and mouth & $\mathrm{C} 02-\mathrm{C} 06$ & 59.8 & 58.6 & 27.6 & 22.9 & 50.8 & 49.4 \\
\hline Tonsil and Oropharynx & $\mathrm{C} 09-\mathrm{C} 10$ & 72.3 & 71.8 & 58.4 & 56.0 & 68.9 & 68.3 \\
\hline Nasopharynx & $\mathrm{C} 11$ & 82.4 & 82.6 & 83.5 & 83.1 & 83.6 & 83.8 \\
\hline Other oral pharynx & $\mathrm{C} 00, \mathrm{C} 07-\mathrm{C} 08, \mathrm{C} 12-\mathrm{C} 14$ & 58.6 & 57.2 & 24.5 & 19.5 & 48.9 & 47.4 \\
\hline Esophagus & $\mathrm{C} 15$ & 82.4 & 81.4 & 42.9 & 40.2 & 77.8 & 76.2 \\
\hline Stomach & $\mathrm{C} 16$ & 85.0 & 86.6 & 87.1 & 90.1 & 86.0 & 88.0 \\
\hline Colon & $\mathrm{C} 18$ & 42.0 & 40.7 & 15.1 & 15.1 & 31.3 & 33.1 \\
\hline Rectum & $\mathrm{C} 19-\mathrm{C} 20$ & 34.1 & 33.2 & 9.7 & 8.8 & 25.0 & 23.4 \\
\hline Anus & $\mathrm{C} 21$ & 88.0 & 88.0 & 88.0 & 88.0 & 88.0 & 88.0 \\
\hline Liver & $\mathrm{C} 22$ & 74.3 & 75.3 & 70.0 & 72.6 & 73.8 & 75.3 \\
\hline Gallbladder & $\mathrm{C} 23$ & 3.1 & 2.7 & 0.9 & 0.8 & 1.8 & 1.6 \\
\hline Pancreas & $\mathrm{C} 25$ & 26.8 & 26.7 & 7.7 & 7.2 & 17.5 & 17.1 \\
\hline Sinonasal & $\mathrm{C} 30-31$ & 48.9 & 48.4 & 19.7 & 17.1 & 38.8 & 36.4 \\
\hline Larynx & $\mathrm{C} 32$ & 77.0 & 75.4 & 13.5 & 11.8 & 73.0 & 71.3 \\
\hline Lung & C33-C34 & 66.3 & 65.6 & 33.2 & 31.2 & 55.2 & 55.4 \\
\hline Breast & $\mathrm{C} 50$ & & & 14.0 & 14.2 & 14.0 & 14.2 \\
\hline Vulva & C51 & & & 48.0 & 48.0 & 48.0 & 48.0 \\
\hline Vagina & C52 & & & 78.0 & 78.0 & 78.0 & 78.0 \\
\hline Cervix & C53 & & & 100.0 & 100.0 & 100.0 & 100.0 \\
\hline Endometrium & C54 & & & 16.1 & 18.5 & 16.1 & 18.5 \\
\hline Ovary & C56 & & & 1.0 & 1.1 & 1.0 & 1.1 \\
\hline Penis & $\mathrm{C} 60$ & 51.0 & 51.0 & & & 51.0 & 51.0 \\
\hline Prostate & C61 & 1.4 & 3.0 & & & 1.4 & 3.0 \\
\hline Kidney & C64 & 28.1 & 26.5 & 3.1 & 2.7 & 20.6 & 18.6 \\
\hline Renal pelvis \& ureter & C65-C66 & 66.1 & 64.7 & 2.8 & 2.4 & 43.2 & 39.9 \\
\hline Bladder & $\mathrm{C} 67$ & 41.6 & 40.7 & 9.5 & 8.0 & 33.5 & 30.5 \\
\hline Hodgkin disease & $\mathrm{C} 81$ & 56.0 & 56.0 & 56.0 & 56.0 & 56.0 & 56.0 \\
\hline Non-Hodgkin Lymphoma & $\mathrm{C} 82-\mathrm{C} 85, \mathrm{C} 96$ & 3.7 & 3.7 & 3.7 & 3.7 & 3.7 & 3.7 \\
\hline Burkitt's lymphoma & C837 & 30.0 & 30.0 & 30.0 & 30.0 & 30.0 & 30.0 \\
\hline Adult T-cell Lymphoma/Leukemia & C915 & 100.0 & 100.0 & 100.0 & 100.0 & 100.0 & 100.0 \\
\hline Acute Myeloid leukemia & C920, C924, C925 & 20.6 & 21.2 & 5.3 & 4.4 & 14.5 & 14.8 \\
\hline All sites & ALL & 43.4 & 49.7 & 25.3 & 26.8 & 35.9 & 41.0 \\
\hline
\end{tabular}



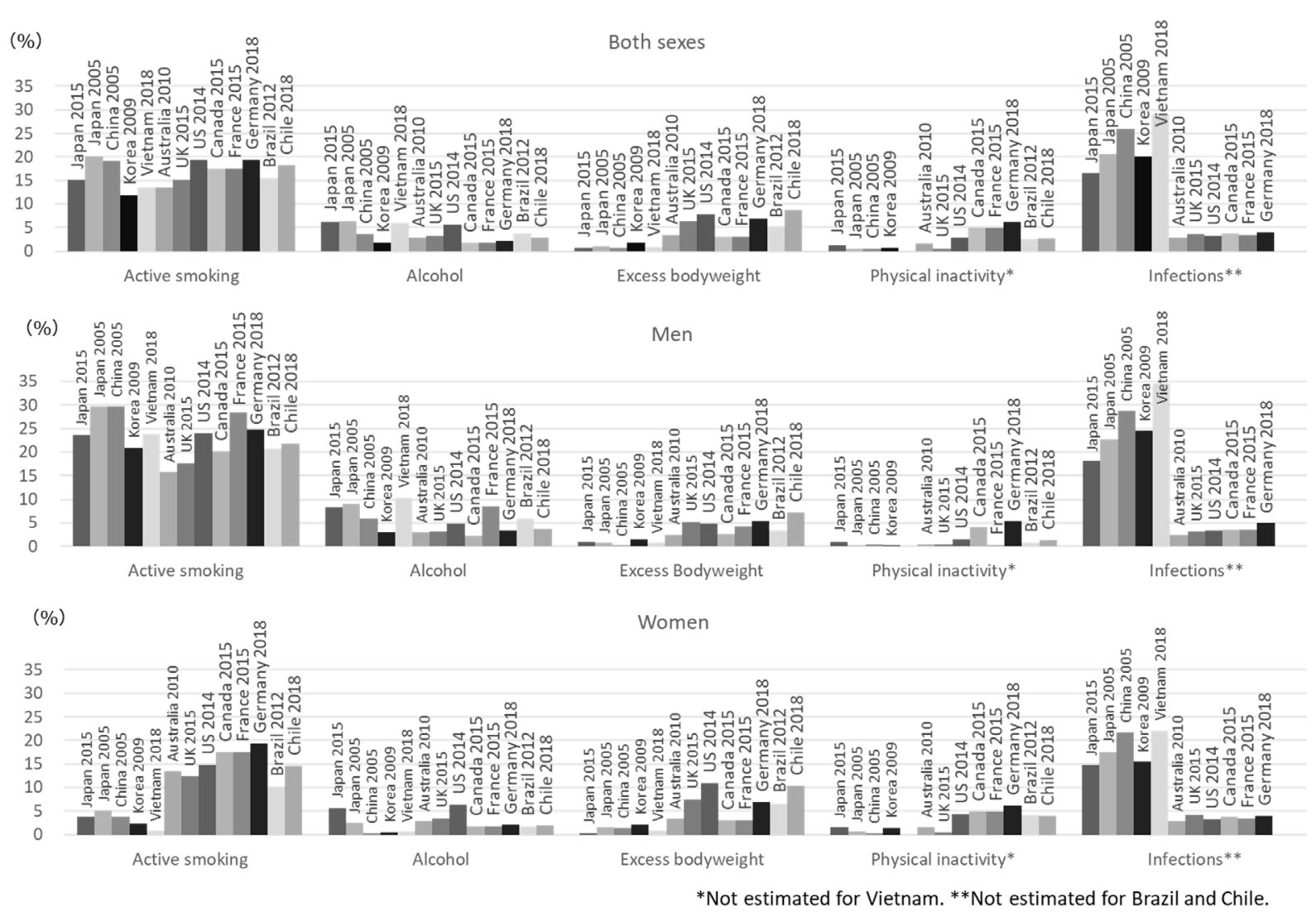

Figure 2. Major attributable causes of cancer incidence-international comparison. Japan 2015 (the present estimate), Japan 2005 (23), China 2005 (13,52-55), South Korea 2009 (14,56-59), Vietnam 2018 (22), Australia 2010 (60), UK 2015 (16), US 2014 (7), Canada 2015 (18), France 2015 (12), Germany 2018 (19, 61-63), Brazil 2012 (20), Chile 2018 (21).

higher fractions tended to be associated with infectious agents and smoking.

\section{Discussion}

This report provides the latest estimates of the cancer burden attributable to modifiable factors in Japan in 2015. Compared with the first assessment for the year 2005, when data sources for the PAF estimates for many exposures occurring around 1990 were generally limited, more epidemiological evidence and data on exposures of interest have since been accumulated, and nationally representative data for the prevalence of many factors have become available. Further, the prevalence of many modifiable risk factors in Japan has dramatically changed with birth cohort; accordingly, use of appropriate prevalence by birth cohort at the time of exposure to these factors allows a more precise estimation of cancer burden.

Compared with the first PAF estimate for 2005 (23), we observed a nearly $5 \%$ reduction in the PAF of cancer incidence and mortality attributable to active smoking in men. This reduction is partly attributable to the decreased prevalence of active smoking in men over these decades (49). A similar reduction was also observed for the PAF attributable to infections. Infections such as Helicobacter pylori and hepatitis $\mathrm{C}$ and $\mathrm{B}$ viruses appear to be the major contributors to cancer in Japan. Improvements in socioeconomic and hygiene status at the time of infection has definitely contributed to a reduction in prevalence, and prevalence rates estimated by birth cohort rather than age group might accordingly provide more precise estimates. In contrast, however, a notable increase in PAF was attributed to alcohol drinking in women.

International comparison clearly indicates that the PAF of infections is relatively high among Asian countries, namely Japan, China, South Korea and Vietnam; but relatively low among European countries and their migration countries, such as UK, US, France, Germany, Australia and Canada (Figure 2). Compared with the previous Japanese estimate for 2005, prevalence of major infectious agents in Japan has decreased, especially in younger birth cohorts $(50,51)$. This decrease will in turn lead to drastic reductions in gastric and liver cancers - the major infection-related cancers in Japan - in the next couple of decades. PAF of other modifiable factors were generally similar among different countries. Of note, however, the larger difference in PAF by active smoking between men and women observed for Japan, China, and South Korea may reflect the difference in smoking rates by sex in East Asia.

Attribution of modifiable factors other than infections, active smoking, and alcohol drinking to 
cancer in Japan was generally small $(<3 \%)$. Excess bodyweight, which is regarded as an important risk factor of cancers, was attributed a very small portion $(\leq 1$ $\%$ ), in spite of the use of a more severe cut-off point (BMI $<23$ ) as a theoretical minimal risk exposure level due to the average BMI levels being less than 25 .

There are several limitations for these estimates. We did not include factors with insufficient exposure or relative risk data, such as solar ultraviolet radiation exposure and ionizing radiation. Also, we could not include occupational exposures due to a lack of adequate prevalence data in the Japanese general population. Given that occupational exposure in Japan is expected to be non-negligible, its inclusion would improve the PAF estimates. Furthermore, a multivariate approach is more realistic considering the multifactorial etiology of cancer in general. We took a statistical approach to account of the overlapping effect of exposures, due to the substantial lack of information for most interactions and the joint prevalence of multiple exposures.

Even though we used the best estimates of prevalence and relative risks available for Japanese and the most suitable methodology, the current estimates are focused on modifiable factors, and did not include unmodifiable factors such as genetic, socioeconomic disparity and reproductive factors which cannot be changed at the individual level. Inclusion of these factors could help provide more comprehensive estimates of attributable causes of cancer, both modifiable and non-modifiable.

In addition to the inclusion of attributable fractions of modifiable factors, national cancer control policy will be further strengthened by the inclusion of economic burden and burden of disability-adjusted life years (DALYs) under these modifiable factors. Inclusion of these variables in combination will aid understanding of the effective population intervention for each factor, and in turn lead to appropriate cancer control policy measures at the national level.

\section{Conclusions}

We estimated the cancer burden attributable to modifiable factors in Japan in 2015 using the best available epidemiological evidence. From our estimates, around $40 \%$ of cancer incidence and mortality may be preventable by avoiding exposure to known modifiable factors. Our findings clearly indicate that infections and active smoking followed by alcohol drinking are the greatest contributing factors and should be the most highly prioritized targets in current cancer control actions.

Funding: This study was supported by JSPS KAKENHI Grant Number 16H05244.

Conflict of Interest: The authors have no conflicts of interest to disclose.

\section{References}

1. Foundation for Promotion of Cancer Research. Cancer Statistics in Japan 2021. https://ganjoho.jp/public/qa links/report/statistics/2021 en.html (accessed December 1, 2021).

2. National Cancer Registry (Ministry of Health, Labour and Welfare), tabulated by Cancer Information Service, National Cancer Center, Japan. https://ganjoho.jp/reg_ stat/statistics/data/dl/en.html (accessed December 1, 2021).

3. Cancer Information Services, National Cancer Center. Grant-in-Aid for Scientific Research (B): cancer causes and attribution to the Japanese population: latest estimates and prediction (Japanese). Tokyo, Japan 2016. https:// ganjoho.jp/reg_stat/statistics/data/dl/index.html (accessed December 1, 2021). (in Japanese)

4. Peto J. Cancer epidemiology in the last century and the next decade. Nature. 2001; 411:390-395.

5. Doll R, Peto R. The causes of cancer: quantitative estimates of avoidable risks of cancer in the United States today. J Natl Cancer Inst. 1981; 66:1191-1308.

6. Harvard Report on Cancer Prevention. Volume 1: Causes of human cancer. Cancer Causes Control. 1996; 7 Suppl 1:S3-S59.

7. Islami F, Goding Sauer A, Miller KD, Siegel RL, Fedewa SA, Jacobs EJ, McCullough ML, Patel AV, Ma J, Soerjomataram I, Flanders WD, Brawley OW, Gapstur SM, Jemal A. Proportion and number of cancer cases and deaths attributable to potentially modifiable risk factors in the United States. CA Cancer J Clin. 2018; 68:31-54.

8. Olsen JH. Avoidable cancers in the Nordic countries. Aims and background. APMIS Suppl. 1997; 76:1-8.

9. Olsen JH, Andersen A, Dreyer L, Pukkala E, Tryggvadottir L, Gerhardsson de Verdier M, Winther JF. Summary of avoidable cancers in the Nordic countries. APMIS Suppl. 1997; 76:141-146.

10. Boffetta P, Tubiana M, Hill C, Boniol M, Aurengo A, Masse R, Valleron AJ, Monier R, de The G, Boyle P, Autier P. The causes of cancer in France. Ann Oncol. 2009; 20:550-555.

11. World Health Organization. International Agency for Research on Cancer. Attributable Causes of Cancer in France in the Year 2000. IARC Working Group Report Volume 3. https://publications.iarc.fr/Book-And-ReportSeries/Iarc-Working-Group-Reports/Attributable-CausesOf-Cancer-In-France-In-The-Year-2000-2007 (accessed August 3, 2021).

12. Soerjomataram I, Shield K, Marant-Micallef C, Vignat J, Hill C, Rogel A, Menvielle G, Dossus L, Ormsby JN, Rehm J, Rushton L, Vineis P, Parkin M, Bray F. Cancers related to lifestyle and environmental factors in France in 2015. Eur J Cancer. 2018; 105:103-113.

13. Wang JB, Jiang Y, Liang H, et al. Attributable causes of cancer in China. Ann Oncol. 2012; 23:2983-2989.

14. National Cancer Center Korea. Attributable causes of cancer in Korea in the year 2009. https://www.ncc.re.kr/ sub07_Publications.ncc?isgubun $=A \&$ searchKey=title \&s earchValue $=$ \& pageNum $=1$ (accessed August 3, 2021).

15. Parkin DM, Boyd L, Walker LC. 16. The fraction of cancer attributable to lifestyle and environmental factors in the UK in 2010. Br J Cancer. 2011; 105 Suppl 2:S77-S81.

16. Brown KF, Rumgay H, Dunlop C, et al. The fraction of 
cancer attributable to modifiable risk factors in England, Wales, Scotland, Northern Ireland, and the United Kingdom in 2015. Br J Cancer. 2018; 118:1130-1141.

17. Whiteman DC, Webb PM, Green AC, et al. Cancers in Australia in 2010 attributable to modifiable factors: introduction and overview. Aust N Z J Public Health. 2015; 39:403-407.

18. Poirier AE, Ruan Y, Volesky KD, King WD, O'Sullivan DE, Gogna P, Walter SD, Villeneuve PJ, Friedenreich CM, Brenner DR, Com PST. The current and future burden of cancer attributable to modifiable risk factors in Canada: Summary of results. Prev Med. 2019; 122:140147.

19. Katalinic A. The Burden of Cancer in Germany. Dtsch Arztebl Int. 2018; 115:569-570.

20. Rezende LFM, Lee DH, Louzada M, Song M, Giovannucci E, Eluf-Neto J. Proportion of cancer cases and deaths attributable to lifestyle risk factors in Brazil. Cancer Epidemiol. 2019; 59:148-157.

21. Rezende LFM, Murata E, Giannichi B, Tomita LY, Wagner GA, Sanchez ZM, Celis-Morales C, Ferrari G. Cancer cases and deaths attributable to lifestyle risk factors in Chile. BMC Cancer. 2020; 20:693.

22. Nguyen TP, Luu HN, Nguyen MVT, Tran MT, Tuong TTV, Tran CTD, Boffetta P. Attributable causes of cancer in Vietnam. JCO Glob Oncol. 2020; 6:195-204.

23. Inoue M, Sawada N, Matsuda T, Iwasaki M, Sasazuki S, Shimazu T, Shibuya K, Tsugane S. Attributable causes of cancer in Japan in 2005 - systematic assessment to estimate current burden of cancer attributable to known preventable risk factors in Japan. Ann Oncol. 2012; 23:1362-1369.

24. World Health Organization. International Agency for Research on Cancer. IARC Monographs on the Evaluation of Carcinogenic Risks to Humans. https:// monographs.iarc.who.int/ (accessed August 3, 2021).

25. World Cancer Research Fund/American Institute for Cancer Research. Diet, Nutrition, Physical Activity and Cancer: a Global Perspective. A summary of the The Third Expert Report. https://www.wcrf.org/wp-content/ uploads/2021/02/Summary-of-Third-Expert-Report-2018. $p d f$ (accessed August 3, 2021).

26. National Center for Chronic Disease Prevention and Health Promotion (US) Office on Smoking and Health. The Health Consequences of Smoking - 50 Years of Progress: A Report of the Surgeon General. Atlanta (GA): Centers for Disease Control and Prevention (US); 2014.

27. Japanese Committee on Health Effects of Smoking. Smoking and health report. https://www.mhlw.go.jp/ content/000550455.pdf (accessed October 20, 2021). (in Japanese)

28. Sasazuki S, Inoue M, Shimazu T, et al. Evidence-based cancer prevention recommendations for Japanese. Jpn J Clin Oncol. 2018; 48:576-586.

29. Cancer Statistics. Cancer Information Service, National Cancer Center, Japan (Monitoring of cancer incidence in Japan (MCIJ)) https://ganjoho.jp/reg_stat/statistics/data/ dl/en.html (accessed December 1, 2021).

30. Katanoda K, Kamo K, Saika K, Matsuda T, Shibata A, Matsuda A, Nishino Y, Hattori M, Soda M, Ioka A, Sobue T, Nishimoto H. Short-term projection of cancer incidence in Japan using an age-period interaction model with spline smoothing. Jpn J Clin Oncol. 2014; 44:36-41.

31. World Health Organization. International Statistical Classification of Diseases and Related Health Problems, 10th Revision (ICD-10). https://apps.who.int/iris/ handle/10665/246208 (accessed August 3, 2021).

32. World Health Organization. International Classification of Diseases for Oncology. Third Edition. https://apps.who. int/iris/bitstream/handle/10665/96612/9789241548496 eng.pdf (accessed August 3, 2021).

33. Cancer Statistics. Cancer Information Service, National Cancer Center, Japan (Vital Statistics of Japan, Ministry of Health, Labour and Welfare) https://ganjoho.jp/reg_ stat/statistics/data/dl/en.html (accessed December 1, 2021).

34. Ministry of Health Labour and Welfare. Sex and age specific mortality statistics in Japan (2015) by ICD-10, by 4-digit. Health, Labour and Welfare Statistics Association. http://www.hws-kyokai.or.jp/information/mortality.html (accessed December 1, 2021). (in Japanese)

35. Beral V; Million Women Study Collaborators. Breast cancer and hormone-replacement therapy in the Million Women Study. Lancet. 2003; 362:419-427.

36. Levin ML. The occurrence of lung cancer in man. Acta Unio Int Contra Cancrum. 1953; 9:531-541.

37. Hanley JA. A heuristic approach to the formulas for population attributable fraction. J Epidemiol Community Health. 2001; 55:508-514.

38. Ezzati M, Hoorn SV, Rodgers A, Lopez AD, Mathers CD, Murray CJ; Comparative Risk Assessment Collaborating Group. Estimates of global and regional potential health gains from reducing multiple major risk factors. Lancet. $2003 ; 362: 271-280$.

39. Katanoda K, Hirabayashi M, Saito E, Hori M, Abe SK, Matsuda T, Inoue M, the Cancer PAF Japan Collaborators. Burden of cancer attributable to tobacco smoke in Japan in 2015. GHM Open. 2021; 1:43-50.

40. Hirabayashi M, Sawada N, Abe SK, Saito E, Hori M, Katanoda K, Matsuda T, Inoue M; the Cancer PAF Japan Collaborators. Burden of cancer attributable to consumption of alcohol in Japan in 2015. GHM Open. 2021; 1:51-55.

41. Hirabayashi M, Abe SK, Sawada N, Saito E, Hori M, Katanoda K, Matsuda T, Inoue M; the Cancer PAF Japan Collaborators. Burden of cancer attributable to excess bodyweight and physical inactivity in Japan in 2015 . GHM Open. 2021; 1:56-62.

42. Lin Y, Wang C, Kikuchi S, Akita T, Tanaka J, Abe SK, Hirabayashi M, Saito E, Hori M, Katanoda K, Matsuda T, Inoue M; the Cancer PAF Japan Collaborators. Burden of cancer attributable to infection in Japan in 2015. GHM Open. 2021; 1:63-69.

43. Takachi R, Ishihara J, Abe SK, Hirabayashi M, Saito E, Hori M, Katanoda K, Matsuda T, Inoue M; the Cancer PAF Japan Collaborators. Burden of cancer attributable to consumption of highly salted food in Japan in 2015. GHM Open. 2021; 1:85-90.

44. Ishihara J, Takachi R, Abe SK, Hirabayashi M, Saito E, Hori M, Katanoda K, Matsuda T, Inoue M; the Cancer PAF Japan Collaborators. Burden of cancer attributable to insufficient vegetable, fruit and dietary fiber consumption in Japan in 2015. GHM Open. 2021; 1:70-75.

45. Abe SK, Takachi R, Ishihara J, Hirabayashi M, Saito E, Hori M, Katanoda K, Matsuda T, Inoue M; the Cancer PAF Japan Collaborators. Burden of cancer attributable to excess red and processed meat consumption in Japan in 2015. GHM Open. 2021; 1:91-96.

46. Hirabayashi M, Nagata C, Abe SK, Sawada N, Saito E, Hori M, Katanoda K, Matsuda T, Inoue M; the Cancer 
PAF Japan Collaborators. Burden of cancer attributable to exogenous hormone use in Japan in 2015. GHM Open. 2021; 1:97-101.

47. Hirabayashi M, Nagata C, Abe SK, Saito E, Hori M, Katanoda K, Matsuda T, Inoue M; the Cancer PAF Japan Collaborators. Burden of cancer attributable to never breastfeeding in Japan in 2015. GHM Open. 2021; 1:102105.

48. Hori M, Katanoda K, Ueda K, Nakaya T, Saito E, Abe SK, Hirabayashi M, Matsuda T, Inoue M; the Cancer PAF Japan Collaborators. Burden of cancer attributable to air pollution in Japan in 2015. GHM Open. 2021; 1:76-84.

49. Funatogawa I, Funatogawa T, Yano E. Trends in smoking and lung cancer mortality in Japan, by birth cohort, 19492010. Bull World Health Organ. 2013; 91:332-340.

50. Akita T, Tanaka J, Satake M, Lin Y, Wada T, Kato K, Inoue M. Meta-regression analysis of sex- and birth yearspecific prevalence of HBsAg and anti-HCV among un-diagnosed Japanese: data grom the first-time blood donors, periodical health checkup, and the comprehensive health checkup with lifestyle education (Ningen Dock). J Epidemiol. 2020; 30:420-425.

51. Wang C, Nishiyama T, Kikuchi S, Inoue M, Sawada N, Tsugane S, Lin Y. Changing trends in the prevalence of $\mathrm{H}$. pylori infection in Japan (1908-2003): a systematic review and meta-regression analysis of 170,752 individuals. Sci Rep. 2017; 7:15491.

52. Wang JB, Jiang Y, Wei WQ, Yang GH, Qiao YL, Boffetta P. Estimation of cancer incidence and mortality attributable to smoking in China. Cancer Causes Control. 2010; 21:959-965.

53. Wang D, Zheng W, Wang SM, Wang JB, Wei WQ, Liang H, Qiao YL, Boffetta P. Estimation of cancer incidence and mortality attributable to overweight, obesity, and physical inactivity in China. Nutr Cancer. 2012; 64:48-56.

54. Xiang W, Shi JF, Li P, Wang JB, Xu LN, Wei WQ, Zhao FH, Qiao YL, Boffetta P. Estimation of cancer cases and deaths attributable to infection in China. Cancer Causes Control. 2011; 22:1153-1161.

55. Liang H, Wang J, Xiao H, Wang D, Wei W, Qiao Y, Boffetta P. Estimation of cancer incidence and mortality attributable to alcohol drinking in China. BMC Public Health. 2010; 10:730.

56. Park S, Jee SH, Shin HR, Park EH, Shin A, Jung KW, Hwang SS, Cha ES, Yun YH, Park SK, Boniol M,
Boffetta P. Attributable fraction of tobacco smoking on cancer using population-based nationwide cancer incidence and mortality data in Korea. BMC Cancer. 2014; 14:406.

57. Park S, Shin HR, Lee B, Shin A, Jung KW, Lee DH, Jee SH, Cho SI, Park SK, Boniol M, Boffetta P, Weiderpass E. Attributable fraction of alcohol consumption on cancer using population-based nationwide cancer incidence and mortality data in the Republic of Korea. BMC Cancer. 2014; 14:420.

58. Shin A, Park S, Shin HR, Park EH, Park SK, Oh JK, Lim MK, Choi BY, Boniol M, Boffetta P. Population attributable fraction of infection-related cancers in Korea. Ann Oncol. 2011; 22:1435-1442.

59. Park S, Kim Y, Shin HR, Lee B, Shin A, Jung KW, Jee SH, Kim DH, Yun YH, Park SK, Boniol M, Boffetta P. Population-attributable causes of cancer in Korea: obesity and physical inactivity. PLoS One. 2014; 9:e90871.

60. Whiteman DC, Webb PM, Green AC, et al. Cancers in Australia in 2010 attributable to modifiable factors: summary and conclusions. Aust N Z J Public Health. 2015; 39:477-484.

61. Mons U, Gredner T, Behrens G, Stock C, Brenner H. Cancers Due to Smoking and High Alcohol Consumption. Dtsch Arztebl Int. 2018; 115:571-577.

62. Gredner T, Behrens G, Stock C, Brenner H, Mons U. Cancers Due to Infection and Selected Environmental Factors. Dtsch Arztebl Int. 2018; 115:586-593.

63. Behrens G, Gredner T, Stock C, Leitzmann MF, Brenner H, Mons U. Cancers Due to Excess Weight, Low Physical Activity, and Unhealthy Diet. Dtsch Arztebl Int. 2018; 115:578-585.

Received April 8, 2021; Revised December 9, 2021; Accepted December 272021.

Released online in J-STAGE as advance publication December 30, 2021.

*Address correspondence to:

Manami Inoue, Division of Prevention, Center for Public Health Sciences, National Cancer Center, 5-1-1 Tsukiji Chuoku, Tokyo 104-0045, Japan.

E-mail: mnminoue@ncc.go.jp 